\title{
Valorization of pineapple waste for the extraction of bioactive compounds and glycosides using autohydrolysis
}

\author{
Leonardo Sepúlveda ${ }^{\mathrm{a}, *}$, Aloia Romanía ${ }^{\mathrm{a}}$, Cristóbal Noé Aguilar ${ }^{\mathrm{b}}$, José Teixeira ${ }^{\mathrm{a}}$ \\ a Centre of Biological Engineering, School of Engineering, University of Minho, Campus de Gualtar, 4710-057 Braga, Portugal \\ ${ }^{\mathrm{b}}$ Food Research Department, School of Chemistry, Universidad Autónoma de Coahuila, 25280 Saltillo, Coahuila, Mexico
}

\section{A R T I C L E I N F O}

Chemical compounds studied in this article: Glucose (PubChem CID: 5793)

Fructose (PubChem CID: 5984)

Saccharose (PubChem CID: 5988)

Gallic acid (PubChem CID: 370)

Hydroxybenzoic acid (PubChem CID: 135)

Chlorogenic acid (PubChem CID: 1794427)

Epicatechin (PubChem CID: 72276)

Coumaric acid (PubChem CID: 637542)

Caffeic acid (PubChem CID: 689043)

Keywords:

Glucose

Gallic acid

Epicatechin

Antioxidant activity

Polyphenols

\begin{abstract}
A B S T R A C T
Autohydrolysis process, an alternative technology that uses only water as extraction solvent, was evaluated for the extraction of glycosides and polyphenols from pineapple waste. A Box-Behnken design was carried out using different temperatures $\left(150-200{ }^{\circ} \mathrm{C}\right)$, solid-liquid ratio $(1: 40-1: 10 \mathrm{w} / \mathrm{v})$ and reaction time $(15-45 \mathrm{~min})$. The best condition for the production of glucose $(27.6 \mathrm{~g} / \mathrm{L})$ and fructose $(33.8 \mathrm{~g} / \mathrm{L})$ was $150{ }^{\circ} \mathrm{C}, 30 \mathrm{~min}$ and $1: 10 \mathrm{w} / \mathrm{v}$ while the highest amount of extracted total polyphenols $(1.75 \mathrm{~g} / \mathrm{L})$ was obtained at $200{ }^{\circ} \mathrm{C}, 30 \mathrm{~min}$ and $1: 10 \mathrm{w} / \mathrm{v}$ solidliquid ratio. In all treatments were detected gallic acid, hydroxybenzoic acid, chlorogenic acid, epicatechin, coumaric acid and caffeic acid. These results indicate autohydrolysis as a valuable alternative for the sustainable extraction of high value-added molecules for further use in industrial, food, cosmetic and health applications.
\end{abstract}

\section{Introduction}

The pineapple (Ananas comosus) is a perennial plant of the Bromeliaceae family whose fruit is marketed around the world. In 2013, pineapple production was around $210,000 \mathrm{t}$ mainly in Latin America and the Caribbean and Portugal (FAO, 2016). This fruit is eaten fresh or used to make juices, jams and preserves.

Pineapple canning industries produce large quantity of solid waste. The dry matter content of pineapple waste is around $10 \%$, composed of about $96 \%$ organic matter and 4\% inorganic matter (Abdullah, 2007). According to (Conesa et al., 2015), in the elaboration of pineapplebased food products, this value can be $50 \%$. Other authors reported a waste production from pineapples processing in the range of $25-35 \%$ of the weight of the fruit (Seleni et al., 2014). This discrepancy can be due to pineapple variety and the type of processing used.

Worldwide, agricultural industries generate large amount of biomass residues which can cause environmental and pollution concerns (Santana-Méridas, González-Coloma, \& Sánchez-Vioque, 2012). Wastes derived from food processing are identified as major resources for the bio-based processes development (Lin et al., 2014) and a sustainable use of these food by-products for the production of value-added products (as chemicals, materials and fuels) could contribute to reduce environmental concerns and improvement of economic growth.

Pineapple waste is an enriched raw material, composed mainly by insoluble fibers, pectins, sugars, protein, vitamins, minerals and phenolic compounds (Díaz-Vela, Totosaus, Cruz-Guerrero, \& PérezChabela, 2013). However, in most of the cases research has been focused on recovering proteolytic enzymes such as bromelain, a group of proteases with different applications in the food, textile, cosmetics and others (Coelho-Silvestre et al., 2012). Taking this in consideration, strategies are needed to recover other added value compounds available in pineapple wastes.

Glycosides obtained from these residues have various applications as food additives, prebiotics and biopreservatives (Cuevas, García, Hodaifa, \& Sánchez, 2015). Moreover, phenolic compounds are of great interest in the pharmaceutical and food industry due to their biological properties with application on human health. There are few studies related to bioactive polyphenols from pineapple residues. Although we can mention some examples as myricetin, salicylic acid, tannic acid, trans-cinnamic acid and p-coumaric acid identified in a high dietary

\footnotetext{
* Corresponding author

E-mail address: 1sepulveda@ceb.uminho.pt (L. Sepúlveda).
} 
fiber powder from pineapple shell which is a part of waste and these compounds were reported as potent antioxidants (Larrauri, Rupérez, \& Saura-Calixto, 1997). On the other hand, it has been shown that the polyphenols found from pineapple wastes such as ferulic acid and syringic acid, are responsible for antioxidant and antimicrobial activity (Upadhyay, Prava-Lama, \& Tawata, 2010).

A wide range of extraction methods have been employed to recover bioactive compounds from agro-industrial wastes (Santana-Méridas et al., 2012). In some investigations the operational conditions are determinant to recovery of bioactive compounds, as the type of solvent, time and temperature of extraction are significant variables on the extraction process. For example, phenolic compounds from pineapple peel were obtained using $25 \mathrm{~g}$ of raw material by extraction with reflux, first with $150 \mathrm{~mL}$ of $\mathrm{n}$-hexane to remove non-polar compounds and then with $150 \mathrm{~mL}$ methanol for $4 \mathrm{~h}$ at $60^{\circ} \mathrm{C}$ these conditions they influenced on the antioxidant activity by DPPH scavenging capacity method (Li et al., 2014).

Alternatively, aqueous processing (also known as autohydrolysis or liquid hot water) is a recognized environmentally-friendly technology used for the extraction of value-added compounds from several raw materials (such as agricultural residues and wood biomass) (Parajó et al., 2008; Conde, Moure, Domínguez, \& Parajó, 2011). This hydrothermal treatment (that uses water as only medium of reaction) has several advantages such as: absence of chemical solvent, no corrosion problems, simple to operate, cost-effective and economical (Ruiz, Rodríguez-Jasso, Fernandes, Vicente, \& Teixeira, 2013).

The aim of this work was the find the ideal conditions for bioactive compounds (polyphenols) and glycosides extraction from pineapple wastes by aqueous processing. Time, liquid to solid ratio and temperature were evaluated using a Box-Behnken design. In addition, the antioxidant activity of the liquid extracts was evaluated with ABTS and DPPH techniques.

\section{Materials and methods}

\subsection{Reagents and chemicals}

Glucose, fructose, Folin-Ciocalteu phenol reagent, ABTS, 2, 2-diphenyl-1-picrylhydrazyl, gallic, hydroxybenzoic, chlorogenic, epicatechin, coumaric and caffeic acid were purchased from Sigma-Aldrich, Germany, all HPLC grade. Sulphuric acid (96\%) and sodium carbonate from Fisher Scientific. Anthrone, methanol and phenol crystallized from PanReac AppliChem. Albumin from Merck. Bradford dye reagent from Alfa Aesar ${ }^{\oplus}$. Acetonitrile and formic acid grade HPLC from Chem-Lab.

\subsection{Raw material}

Pineapple waste (composed mainly by core and skin) was kindly provided by a local food company (Oporto, Portugal). Pineapple wastes were placed in aluminum trays and submitted to a drying stage at $60{ }^{\circ} \mathrm{C}$ for $48 \mathrm{~h}$ in order to avoid degradation. The dried samples were mixed to obtain a representative lot, milled (Cemotec mill model 1090, Sweden) and sieved to obtain a particle size of $<1 \mathrm{~mm}$. Then, samples were placed in a plastic bag and stored in a dry place until further analysis.

\subsubsection{Chemical characterization of raw material}

2.2.1.1. Total and reducing sugars content. Total sugars determination of pineapple waste was carried out following the methodology reported by Dubois, Gilles, Hamilton, Rebers, and Smith (1956). Glucose was used as standard. In a test tube, $500 \mu \mathrm{L}$ of sulphuric acid $\left(\mathrm{H}_{2} \mathrm{SO}_{4} 96 \%\right)$ were added to the sample and mixed. From this, $300 \mu \mathrm{L}$ were taken and placed in a 96 well microplate and in oven at $105^{\circ} \mathrm{C}$ for $10 \mathrm{~min}$ and then cooled at room temperature. Finally, absorbance was read in an ELISA (Synergy HT, BioTek ${ }^{\circledast}$, Winooski, VT, USA) microplate analyzer at $480 \mathrm{~nm}$.

The determination of reducing sugars present in pineapple waste was carried out following the methodology reported by Dreywood (1946), also using glucose as standard. In a test tube, $500 \mu \mathrm{L}$ of diluted sample and $1 \mathrm{~mL}$ of the anthrone reagent were added. The tubes were placed in an ice bath for $10 \mathrm{~min}$. Subsequently, the tubes were placed in a water bath at $80^{\circ} \mathrm{C}$ for $15 \mathrm{~min}$. Samples were cooled at room temperature. Finally, absorbance was read in an ELISA (Synergy HT, BioTek $^{\circledR}$, Winooski, VT, USA) microplate analyzer at $620 \mathrm{~nm}$. In both determinations, the pineapple waste samples were diluted one thousand times with distilled water.

\subsubsection{Soluble protein content}

Soluble protein determination of pineapple waste was carried out in accordance with the methodology reported by Bradford (1976). Albumin was used as standard in a concentration in the range up to $1 \mathrm{~g} / \mathrm{L}$. Samples were diluted one hundred times; $50 \mu \mathrm{L}$ of diluted sample and $500 \mu \mathrm{L}$ of Bradford reagent were mixed in a test tube. Aliquots of $300 \mu \mathrm{L}$ were taken and placed in 96 well microplate. Absorbance was read at $595 \mathrm{~nm}$ in an ELISA (Synergy HT, BioTek ${ }^{\oplus}$, Winooski, VT, USA) microplate analyzer.

\subsection{Aqueous processing for extraction of glycosides and polyphenolic compounds: experimental Box-Behnken design (BBD)}

Box-Behnken design was used for evaluation and optimization of the effect of independent variables (time, solid to liquid ratio (w/v) and temperature) on the release of bioactive compounds and glycosides from pineapple waste by autohydrolysis. Three variables at three levels were used. All treatments were performed in triplicate. Nine central points were used. The condensed matrix of treatments and the variables evaluated were shown in Table 1. To evaluate the proposed model, an Analysis of Variance (ANOVA) test was analyzed for each response variable. A second-order polynomial Eq. (1) that all interaction terms was used to calculate the predicted response:

$Y=\beta_{0}+\sum_{i=l}^{k} \beta_{i} X_{i}+\sum_{i=l}^{k} \beta_{i i} X_{i}^{2}+\sum_{i<j}^{k-1} \beta_{i j} X_{i} X_{j}+\varepsilon$

where $Y$ is the response variable, $\beta_{0}$ is constant, $\beta_{i} X_{i}$ is linear effect of the independent variable, $\beta_{i i} X_{i}^{2}$ is quadratic effect of the independent variable, $\beta_{i j} X_{i} X_{j}$ is interaction effects of the independents variables and $\varepsilon$ is total error.

Extraction experiments were carried out in steel cylinders $(12.5 \mathrm{~cm}$ long and $6.45 \mathrm{~cm}$ wide) as described by Ruiz, Vicente, and Teixeira (2012) placed inside an oil bath (MC Model, Julabo, Labortechnik $\mathrm{GmbH}$, Seelbach, Germany) with temperature control. Distilled water and pineapple waste were mixed at the different ratios mass/volume shown in Table 1. At the end of the reaction time, the cylinders were placed in an ice bath for cooling down. Subsequently, solid and liquid phases were separated by filtration in order to obtain hydrolysates.

\subsection{Hydrolysates analysis: glycosides and polyphenols quantification and identification}

Hydrolysates from autohydrolysis assays were analyzed for glycosides and polyphenols content. Glucose and fructose were quantified by HPLC (Jasco AS-2057 plus, Tokyo, Japan) and bomb (Jasco 880-PU, Tokyo, Japan) equipped with refractive index detector (Knauer K-2300, Berlin, Germany) and a column Metacarb $87 \mathrm{H}(300 \times 7.8 \mathrm{~mm}$, Varian, USA) eluted with $0.005 \mathrm{M} \mathrm{H}_{2} \mathrm{SO}_{4}$, flow rate of $0.6 \mathrm{~mL} / \mathrm{min}$ in a temperature control chamber (Jhones Chromatography model 7971) at $60{ }^{\circ} \mathrm{C}$ (time analysis of $20 \mathrm{~min}$ ). For polyphenols analysis, it was used an UHPLC (Shimadzu Nexera $\times 2$ LC-30 CE, USA) equipped with autosample (Nexera $\times 2$ SIL-30 AC prominence, USA), diode array detector (SPD-M20A), column oven (CTO-20 AC prominence) and a column Teknokroma $\otimes$ (Brisa LC2 C18 TR-010481, $25 \times 0.46 \mathrm{~cm}, 5 \mu \mathrm{m}$, Barcelona, Spain). Standard solutions of gallic, hydroxybenzoic, 
Table 1

Condensed matrix of treatments from BBD to analyze the release of bioactive compounds and variables with affecting this process.

\begin{tabular}{|c|c|c|c|c|c|c|}
\hline \multirow[t]{2}{*}{ Run } & \multicolumn{3}{|c|}{ Independent variable ${ }^{a}$} & \multicolumn{3}{|c|}{ Response variable $^{b}$} \\
\hline & Temperature $\left({ }^{\circ} \mathrm{C}\right)$ & Time (min) & Ratio (w/v) ${ }^{\mathrm{c}}$ & Fructose $(\mathrm{g} / \mathrm{L})$ & Glucose (g/L) & Total polyphenols $(\mathrm{g} / \mathrm{L})$ \\
\hline 1 & $150(-1)$ & $15(-1)$ & $1: 25(0)$ & $12.92 \pm 0.76$ & $10.40 \pm 0.65$ & $0.59 \pm 0.07$ \\
\hline 2 & $200(1)$ & $15(-1)$ & $1: 25(0)$ & $9.11 \pm 2.03$ & $8.97 \pm 1.21$ & $0.41 \pm 0.05$ \\
\hline 3 & $150(-1)$ & $45(1)$ & $1: 25(0)$ & $14.12 \pm 0.42$ & $11.67 \pm 0.30$ & $0.28 \pm 0.04$ \\
\hline 4 & $200(1)$ & $45(1)$ & $1: 25(0)$ & $2.77 \pm 0.42$ & $4.65 \pm 0.77$ & $0.94 \pm 0.04$ \\
\hline 5 & $150(-1)$ & $30(0)$ & $1: 40(-1)$ & $8.52 \pm 0.05$ & $7.01 \pm 0.04$ & $0.25 \pm 0.03$ \\
\hline 6 & $200(1)$ & $30(0)$ & $1: 40(-1)$ & $2.58 \pm 0.44$ & $4.08 \pm 0.53$ & $0.48 \pm 0.05$ \\
\hline 7 & $150(-1)$ & $30(0)$ & $1: 10(1)$ & $33.85 \pm 0.99$ & $27.62 \pm 0.70$ & $1.19 \pm 0.15$ \\
\hline 8 & $200(1)$ & $30(0)$ & $1: 10(1)$ & $4.30 \pm 0.85$ & $12.11 \pm 2.34$ & $1.75 \pm 0.07$ \\
\hline 9 & $175(0)$ & $15(-1)$ & $1: 40(-1)$ & $8.27 \pm 0.31$ & $6.89 \pm 0.30$ & $0.74 \pm 0.03$ \\
\hline 10 & $175(0)$ & $45(1)$ & $1: 40(-1)$ & $4.84 \pm 0.14$ & $5.19 \pm 0.12$ & $0.76 \pm 0.11$ \\
\hline 11 & $175(0)$ & $15(-1)$ & $1: 10(1)$ & $31.50 \pm 1.28$ & $26.82 \pm 0.46$ & $0.70 \pm 0.11$ \\
\hline 12 & $175(0)$ & $45(1)$ & $1: 10$ (1) & $18.19 \pm 1.36$ & $21.83 \pm 0.51$ & $0.96 \pm 0.04$ \\
\hline 13 & $175(0)$ & $30(0)$ & $1: 25(0)$ & $11.09 \pm 0.75$ & $10.17 \pm 0.35$ & $1.31 \pm 0.26$ \\
\hline
\end{tabular}

${ }^{\text {a }}$ Numbers in parentheses are value coded for levels of independent variable.

${ }^{\mathrm{b}}$ Values presented as mean \pm standard deviation.

${ }^{c} \mathrm{~g}$ of pineapple waste dry/mL of distilled water.

chlorogenic, epicatechin, coumaric and caffeic acid in a concentration range of $0-1.5 \mathrm{~g} / \mathrm{L}$ were used. Formic acid $1 \%$ (A) and acetonitrile (B) were used for the preparation of the eluent. An elution gradient was established as follows, $18 \%$ B to $82 \%$ A over 20 min, $28 \%$ B to $42 \%$ A over $15 \mathrm{~min}, 60 \%$ B to $40 \%$ A over $10 \mathrm{~min}, 90 \%$ B to $10 \%$ A over $3 \mathrm{~min}$ and $22 \mathrm{~min}$ washing column to return to the initial conditions. A flow rate of $0.7 \mathrm{~mL} / \mathrm{min}$ was used. Double detection at 280 and $320 \mathrm{~nm}$ were established. All samples were passed through filters (Organe scientific) of $0.45 \mu \mathrm{m}$.

\subsection{Total polyphenols content}

In order to complete the data from UHPLC analysis, the determination of total polyphenols in the hydrolysates was carried out according to the methodology reported by Makkar, Blümmel, Borowy, and Becker (1993). Caffeic acid was used as standard in a concentration range up to $2 \mathrm{~g} / \mathrm{L}$. In a microplate, $5 \mu \mathrm{L}$ of sample were placed to each well (a blank of distilled water was used) and $60 \mu \mathrm{L}$ of sodium carbonate $\left(\mathrm{Na}_{2} \mathrm{CO}_{3}\right)$ at $15 \%$ and $15 \mu \mathrm{L}$ of Folin-Ciocalteu reagent were added and mixed. The microplate was incubated at $50{ }^{\circ} \mathrm{C}$ for $5 \mathrm{~min}$ and was cooled at room temperature. Absorbance was read in an ELISA (Synergy HT, BioTek ${ }^{\circledR}$, Winooski, VT, USA) microplate analyzer at $700 \mathrm{~nm}$.

\subsubsection{Antioxidant activity}

Free radical scavenging activity (DPPH assay) of hydrolysates was determined according to methodology reported by Ballesteros, Cerqueira, Teixeira, and Mussatto (2015). Gallic acid was used to compare the antioxidant activity. The samples were placed in an ELISA (Synergy HT, BioTek ${ }^{\circledR}$, Winooski, VT, USA) microplate analyzer, were mixed by $30 \mathrm{~s}$ and were read at $515 \mathrm{~nm}$. The radical scavenging activity (RSA) was calculated according to Eq. (1).

$\mathrm{RSA} \%=\frac{A_{c}-A_{s}}{A_{c}} * 100$

where $A_{c}$ is the absorbance of the control and $A_{s}$ is the absorbance of the sample solution.

Radical cation decolorization (ABTS assay) was determined according to methodology reported by Ballesteros et al. (2015). Gallic acid was used to compare the antioxidant activity. The samples were placed in an ELISA (Synergy HT, BioTek ${ }^{\circledR}$, Winooski, VT, USA) microplate analyzer, mixed by $30 \mathrm{~s}$ and read at $734 \mathrm{~nm}$.

\subsection{Analysis and statistical evaluation of data}

The experimental design was carried out using 13 runs (randomized experimental design with factorial arrangement $3^{3}$ ). All analyses were carried out in triplicate and the results are presented as mean values plus standard deviations. Pareto chart was used to standardize values, and to evaluate variables in descending order. Data were analyzed using Statistica version 7.0. Lab-Solutions software 5.71SP1 version was used for the interpretation of results. The significance testing was performed by Tukey's test and the differences were statistically significant at $\mathrm{p}<0.05$, for this analysis SAS (Statistical Analysis Software) Version 8.0 was used.

\section{Results and discussion}

\subsection{Chemical composition of raw material}

The chemical composition of pineapple waste was analyzed and its composition was as follows: $82 \%$ of total sugars, including $55 \%$ of reducing sugars and $27 \%$ of non-reducing sugars (measured by difference). Sugars were the main component in this material since it is composed mainly by the core, the largest part the pineapple waste. Lower values of total sugar $(9.75 \%)$ were reported by other authors (Hemalatha \& Anbuselvi, 2013) since this depends of fruit variety. On the other hand, pineapple liquid waste obtained from a fermentation process can present values higher than $70 \%$ of total sugars (on a dry weight basis) composed mainly of sucrose, glucose and fructose. (Jusoh, Othman, Idris, \& Nasruddin, 2014). In this study, the protein content was $5 \%$ and of total polyphenols $4 \%$. These values can be compared with reported for pineapple pomace $(4.71 \%$ of protein) (Seleni et al., 2014) and total polyphenols (3.9\%) content in entire pineapple (Chakraborty, Srinivasa, \& Niwas, 2015) respectively.

\subsection{Effect of autohydrolysis process on release glycosides}

The glycosides (glucose and fructose) and total polyphenol concentration obtained in the hydrolysates after autohydrolysis from pineapple waste were shown in Table 1 . The maximum concentration of glucose (27.62 and $26.82 \mathrm{~g} / \mathrm{L}$ ) and fructose (33.85 and $31.50 \mathrm{~g} / \mathrm{L})$ was obtained in treatments 7 and 11, respectively, a 3-fold higher fructose and glucose extraction in comparison with the treatment 13 (central conditions). These results are explained because at temperatures higher $150^{\circ} \mathrm{C}$, it starts to occur the hydrolysis of the material. Further, this autohydrolysis process increases the $\mathrm{H}^{+}$and $\mathrm{OH}^{-}$ions, thereby facilitating the release of sugars compounds (Lachos-Pérez et al., 2016). For treatments 6 and 4, concentrations of 2.58 and $2.77 \mathrm{~g} / \mathrm{L}$ of fructose and 4.08 and $4.65 \mathrm{~g} / \mathrm{L}$ of glucose were obtained respectively. Autohydrolysis process was also used to obtain sulphated polysaccharides 
Table 2

Analysis of variance (ANNOVA) for all response variables (glucose, fructose and polyphenols). (L) Linear terms. (Q) Quadratic terms.

\begin{tabular}{|c|c|c|c|c|c|}
\hline $\begin{array}{l}\text { Independent } \\
\text { variable }\end{array}$ & d.f. ${ }^{\text {a }}$ & Sum squares & Mean squares & F-value & p-Value ${ }^{b}$ \\
\hline \multicolumn{6}{|l|}{ Fructose } \\
\hline (1) Temperature & 1 & 885.468 & 885.468 & 47.20975 & 0.000000 \\
\hline$\left({ }^{\circ} \mathrm{C}\right)(\mathrm{L})$ & 1 & 48.806 & 48.806 & 2.60215 & 0.114994 \\
\hline \multicolumn{6}{|l|}{$\begin{array}{l}\text { Temperature } \\
\left({ }^{\circ} \mathrm{C}\right)(\mathrm{Q})\end{array}$} \\
\hline (2) Time (min) (L) & 1 & 179.618 & 179.618 & 9.57656 & 0.003689 \\
\hline Time $(\mathrm{min})(\mathrm{Q})$ & 1 & 6.659 & 6.659 & 0.35503 & 0.554810 \\
\hline (3) Ratio (w/v) (L) & 1 & 1617.485 & 1617.485 & 86.23810 & 0.000000 \\
\hline Ratio (w/v) (Q) & 1 & 166.228 & 166.228 & 8.86264 & 0.005043 \\
\hline Error & 38 & 712.729 & 18.756 & & \\
\hline Total & 48 & 3630.265 & & & \\
\hline \multicolumn{6}{|l|}{ Glucose } \\
\hline (1) Temperature & 1 & 232.597 & 232.597 & 44.9470 & 0.000000 \\
\hline$\left({ }^{\circ} \mathrm{C}\right)(\mathrm{L})$ & 1 & 28.862 & 28.862 & 5.5773 & 0.023422 \\
\hline \multicolumn{6}{|l|}{ Temperature } \\
\hline (2) Time (min) (L) & 1 & 35.614 & 35.614 & 6.8821 & 0.012464 \\
\hline Time (min) (Q) & 1 & 1.452 & 1.452 & 0.2806 & 0.599399 \\
\hline (3) Ratio (w/v) (L) & 1 & 1692.818 & 1692.818 & 327.1200 & 0.000000 \\
\hline Ratio (w/v) (Q) & 1 & 238.496 & 238.496 & 46.0869 & 0.000000 \\
\hline Error & 38 & 196.647 & 5.175 & & \\
\hline Total & 44 & 2439.705 & & & \\
\hline \multicolumn{6}{|l|}{ Polyphenols } \\
\hline (1) Temperature & 1 & 0.59843 & 0.598426 & 5.67237 & 0.022346 \\
\hline$\left({ }^{\circ} \mathrm{C}\right)(\mathrm{L})$ & 1 & 1.35455 & 1.354549 & 12.83952 & 0.000951 \\
\hline \multicolumn{6}{|l|}{$\begin{array}{l}\text { Temperature } \\
\left({ }^{\circ} \mathrm{C}\right)(\mathrm{Q})\end{array}$} \\
\hline (2) Time (min) (L) & 1 & 0.09094 & 0.090939 & 0.86199 & 0.359041 \\
\hline Time (min) (Q) & 1 & 2.50230 & 2.502302 & 23.71887 & 0.000020 \\
\hline (3) Ratio (w/v) (L) & 1 & 2.11944 & 2.119436 & 20.08975 & 0.000066 \\
\hline Ratio (w/v) (Q) & 1 & 0.13279 & 0.132794 & 1.25873 & 0.268930 \\
\hline Error & 38 & 4.00894 & 0.105498 & & \\
\hline Total & 44 & 10.44126 & & & \\
\hline
\end{tabular}

${ }^{\text {a }}$ d.f. degrees of freedom.

${ }^{\mathrm{b}} \mathrm{p}<0.05$ indicates statistical significance.

from Fucus vesiculosus. Assays were performed under different conditions of temperature $\left(160\right.$ to $200{ }^{\circ} \mathrm{C}$ ) and reaction time (10 to $30 \mathrm{~min}$ ) and compared with traditional chemical methods allowing to conclude that autohydrolysis is a more economical and environmental friendly pretreatment (Rodríguez-Jasso, Mussatto, Pastrana, Aguilar, \& Teixeira, 2013).

The results of the analysis of variance for glucose and fructose are shown in Table 2. The following second order polynomial equation with applying multiple regression analysis on the experimental data was found for glucose.

$y=10.18-3.11 x_{1}-1.22 x_{2}+8.40 x_{3}-1.61 x_{1}^{2}+0.36 x_{2}^{2}+4.64 x_{3}^{2}$

where $x_{1}, x_{2}$ and $x_{3}$ are the values of temperature, time and ratio, respectively. The second-order regressions were statistically significant where the value adjusted were of $92 \%$ for glucose. For the fructose case was applied the following equation:

$y=11.05-6.07 x_{1}-2.74 x_{2}+8.21 x_{3}-2.10 x_{1}^{2}+0.78 x_{2}^{2}+3.88 x_{3}^{2}$

where the independent variables values were coded same as the previous equation and the second-order regressions were statistically significant where the value adjusted were of $80 \%$ for fructose. For glucose extraction, temperature and solid to liquid ratio $\mathrm{w} / \mathrm{v}$ (linear terms) and solid to liquid ratio $\mathrm{w} / \mathrm{v}$ (quadratic terms) were more significant compared with other variables. On the other hand for fructose, temperature and solid to liquid ratio (w/v) (linear terms) were more significant compared with other variable evaluated (time). Pareto charts shown the effects of the independent variables of the autohydrolysis process on the release of fructose and glucose (see Fig. 1).
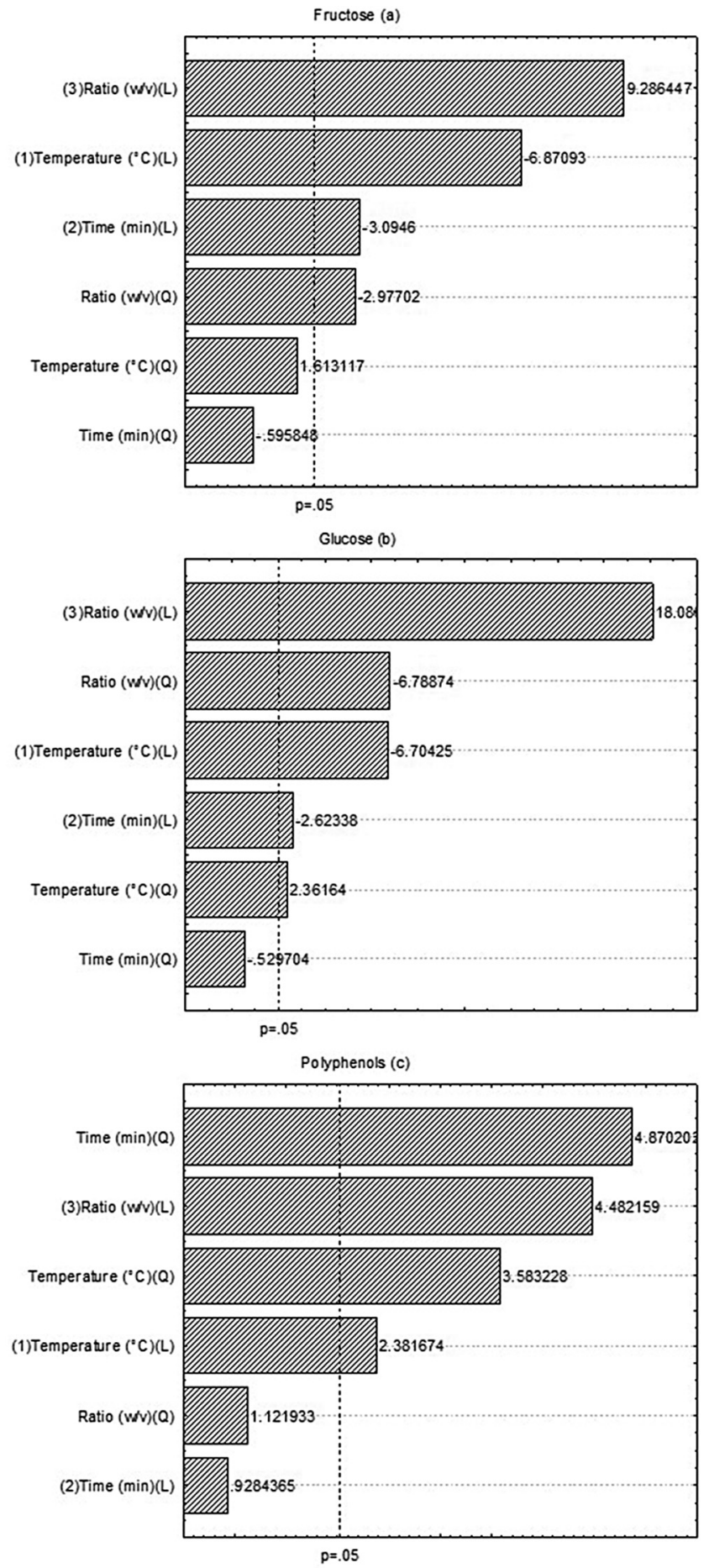

Fig. 1. Pareto chart of independent variables effect on release of fructose (a), glucose (b) and polyphenols (c).

Fig. 1a shown the standardized effect of each variable on fructose extraction. The bars extending beyond the vertical line correspond to the effects statistically significant at $95 \%$ confidence level. The length of each bar is proportional to the standardized effect. According to the statistical analysis, the solid-liquid ratio was the most significant variable, followed by temperature and time. In this figure, linear (L) and quadratic (Q) effect of solid-liquid ratio, linear effect of time and linear effect of temperature had statistical significance on the fructose release ( $p<0.05$ ). The quadratic effect of temperature and time was not significant in the autohydrolysis process. In a similar process, Sabio, Álvarez-Murillo, Román, and Ledesma (2015) evaluated the influence 

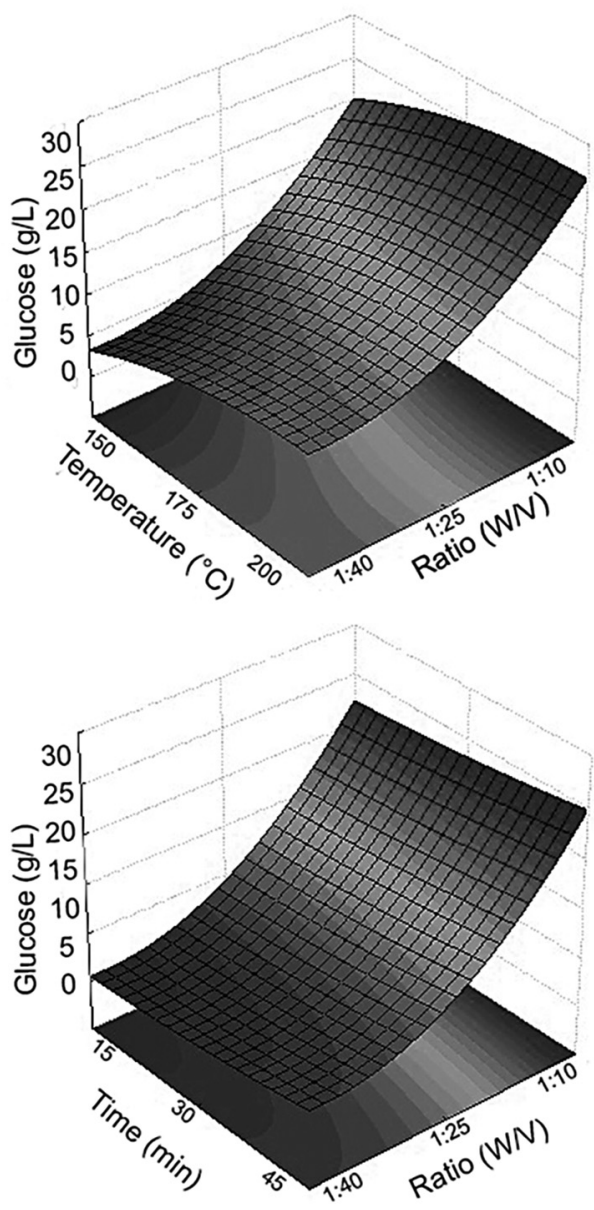

b

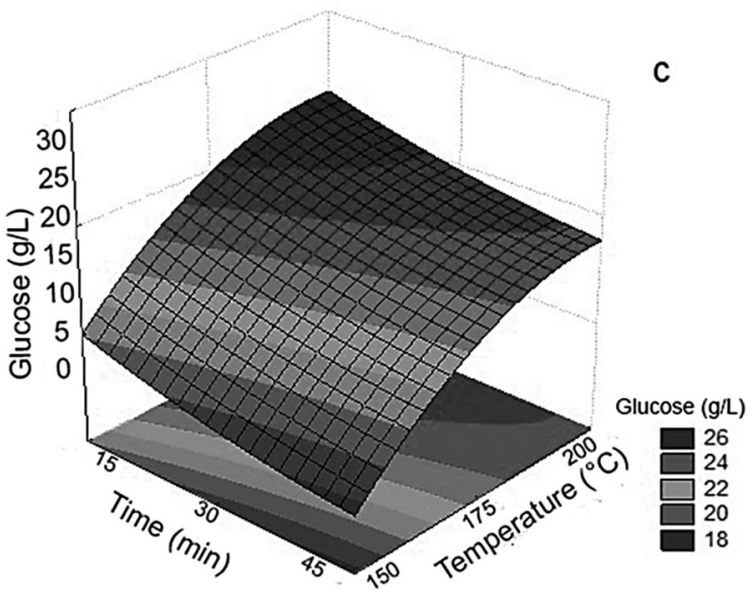

Fig. 2. Response surface plots of the effect of: (a) solid-liquid ratio (w/v) and temperature $\left({ }^{\circ} \mathrm{C}\right)$, (b) solid-liquid ratio $(\mathrm{w} / \mathrm{v})$ and time $(\mathrm{min})$; and $(\mathrm{c})$ temperature $\left({ }^{\circ} \mathrm{C}\right)$ and time $(\mathrm{min})$ on release of glucose.

of temperature, time and biomass/water ratio on the hydrothermal carbonization (HTC) of tomato peel. They concluded that the temperature and time were significant in the solids extraction yield. Fig. 1b shown the standardized effect of each variable on glucose extraction. In this figure, linear effect of solid-liquid ratio $(\mathrm{w} / \mathrm{v})$, temperature and time and quadratic effect of ratio $(\mathrm{w} / \mathrm{v})$ and temperature had statistical significance on the glucose release $(\mathrm{p}<0.05)$. The quadratic effect of time was not significant in the autohydrolysis process.

The effect of solid to liquid ratio (w/v) and autohydrolysis temperature on the release of glucose was shown in Fig. 2a. As observed, at high values of solid to liquid ratio $\mathrm{w} / \mathrm{v}$ and temperature, a maximum

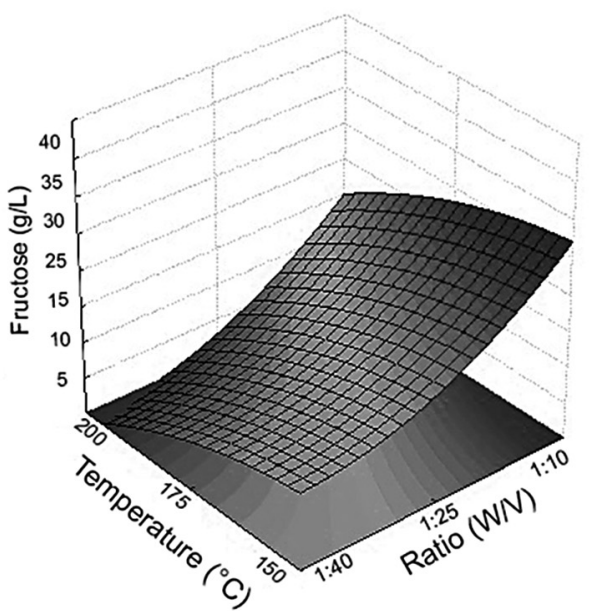

a
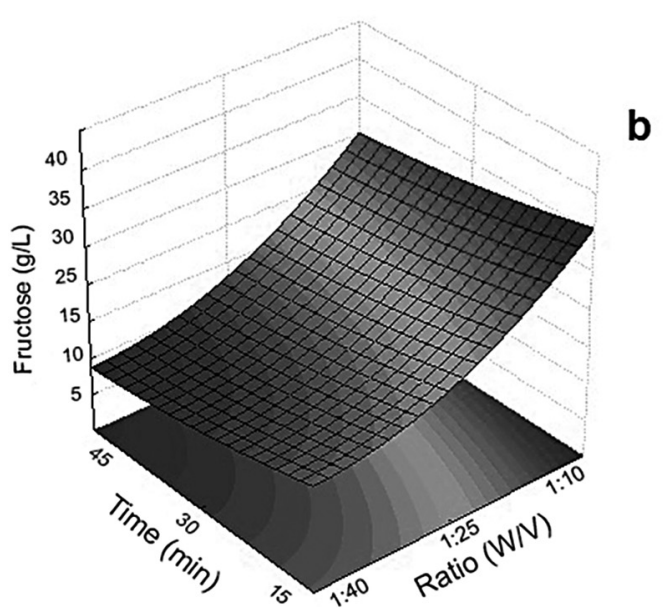

b

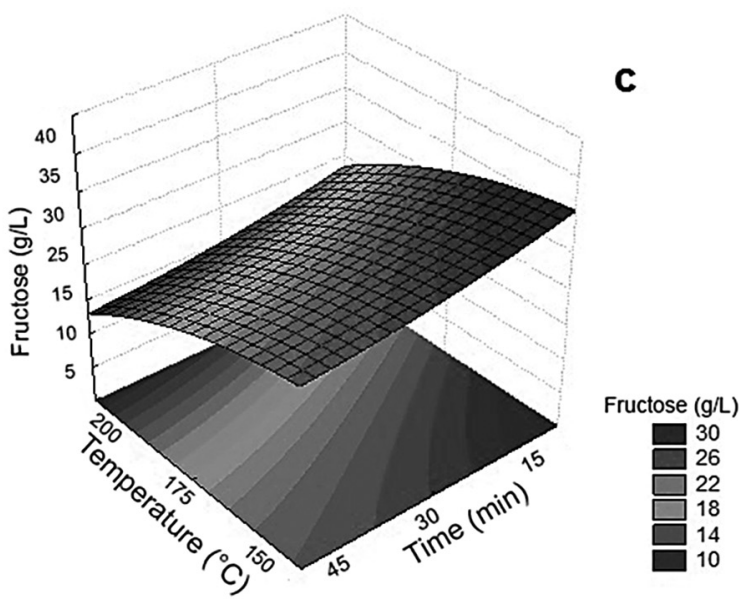

Fig. 3. Response surface plots of the effect of: (a) solid-liquid ratio (w/v) and temperature $\left({ }^{\circ} \mathrm{C}\right)$, (b) solid-liquid ratio $(\mathrm{w} / \mathrm{v})$ and time $(\mathrm{min})$; and $(\mathrm{c})$ temperature $\left({ }^{\circ} \mathrm{C}\right)$ and time $(\mathrm{min})$ on release of fructose.

concentration of $25 \mathrm{~g} / \mathrm{L}$ of glucose was obtained. In Fig. $2 \mathrm{~b}$, the effect of solid to liquid ratio $\mathrm{w} / \mathrm{v}$ and time were shown; in these conditions, up to $23 \mathrm{~g} / \mathrm{L}$ of glucose was reached. On the other hand, the effect of temperature and time on the release of glucose was shown in Fig. 2c. At high temperature values $\left(200^{\circ} \mathrm{C}\right)$ and lower time values $(15 \mathrm{~min})$, maximum release of glucose $(27 \mathrm{~g} / \mathrm{L})$ was obtained. In other work, high sugar extraction as oligosaccharide was obtained from pretreated olive stones by autohydrolysis at temperatures ranging from $150{ }^{\circ} \mathrm{C}$ to $225^{\circ} \mathrm{C}$ for 0-600 s, (Cuevas et al., 2015). When water-extracted lemon peel wastes were treated at $160^{\circ} \mathrm{C}$, the oligomer concentration reached the 
maximum value 31 g/L (Gómez, Gullón, Yáñez, Parajó, \& Alonso, 2013).

Fig. 3a shown the effect of liquid to solid ratio $\mathrm{w} / \mathrm{v}$ and temperature on fructose extraction. At liquid to solid ratio $(1: 10 \mathrm{w} / \mathrm{v})$ and lower values of temperature $\left(150{ }^{\circ} \mathrm{C}\right)$, maximum fructose concentration of $30 \mathrm{~g} / \mathrm{L}$ was obtained. On the other hand, the effect of dependent variables solid to liquid ratio (w/v) and time were shown in Fig. 3b. Fig. 3c displayed the effect of time and temperature, these were similar to those described above. A combination of two environmental-friend process for hemicelluloses and lignin recovery from red grape stalks was investigated by (Amendola et al., 2012) that concluded that autohydrolysis process allows release of glycosides. In another work, autohydrolysis was demonstrated to be an efficient technique to recover polysaccharides from spent coffee grounds, particularly when applied at $160{ }^{\circ} \mathrm{C}$ for $10 \mathrm{~min}$, and using a liquid-solid ratio of $15 \mathrm{~mL}$ water per gram of spent coffee ground (Ballesteros, Ramirez, Orrego, Teixeira, \& Mussatto, 2017).

\subsection{Effect of autohydrolysis process on release of polyphenols}

Table 1 shown the total polyphenols extracted from pineapple wastes by autohydrolysis process. In the treatment 8 , maximum values of polyphenols $(1.75 \mathrm{~g} / \mathrm{L})$ were achieved, a 12-fold higher polyphenol extraction compared to the values obtained by control treatment (same conditions without temperature). In another study, chestnut burs were processed by solvent extraction (with ethanol, toluene-ethanol or $n$ hexane) and/or isothermal autohydrolysis, this process allowing increasing yields of polyphenolic compounds with high antioxidant activity (Mouré, Conde, Falqué, Domínguez, \& Parajó, 2014). Mrabet et al. (2014) applied two hydrothermal treatments on secondary date varieties from Tunisian coastal oasis in order to obtain valuable extracts, rich in dietary fiber and antioxidants. The methodologies evaluated allowed to obtain 4-8\% of phenolic compounds in the extracts. Fig. 1c shown the standardized effect of each variable on polyphenols extraction. The bars extending beyond the vertical line correspond to the effects statistically significant at $95 \%$ confidence level. The length of each bar is proportional to the standardized effect. According to the statistical analysis, the time was the most significant variable, followed by solid-liquid ratio and temperature. In this figure, linear (L) effect of solid-liquid ratio and temperature; quadratic (Q) effect of time and temperature were statistical significance on the polyphenols release $(\mathrm{p}<0.05)$.

The results of the analysis of variance for polyphenols are shown in Table 2 . The following second order polynomial equation with applying multiple regression analysis on the experimental data.

$y=1.38+0.16 x_{1}+0.06 x_{2}+0.30 x_{3}-0.35-0.48 x_{2}^{2}-0.11 x_{3}^{2}$

where $x_{1}, x_{2}$ and $x_{3}$ are the values of temperature, time and ratio, respectively. The second-order regressions were statistically significant where the value adjusted.

The effect of solid-liquid ratio and time at temperature of $200{ }^{\circ} \mathrm{C}$ is shown in Fig. 4a, begin shown that at this temperature the maximum release of polyphenols was $1.4 \mathrm{~g} / \mathrm{L}$. Fig. $4 \mathrm{~b}$ shown the effect of time and temperature on the release of polyphenols. The highest yields were obtained at intermediate values of temperature and time $(30 \mathrm{~min}$ and $175^{\circ} \mathrm{C}$ ). In Fig. 4c, the effect of solid-liquid ratio and temperature at time of $30 \mathrm{~min}$ is plotted, being shown that the maximum release of polyphenolic compounds was obtained at the highest values of solidliquid ratio $\mathrm{w} / \mathrm{v}(1: 10 \mathrm{w} / \mathrm{v})$ and at intermediate values of temperature $\left(175^{\circ} \mathrm{C}\right)$.

Besides total phenolic compounds quantification, hydrolysates were analyzed to identify the phenolic compounds present (see Fig. 5). For treatments 8 and 12 values of 2.78 and $2.31 \mathrm{~g} / \mathrm{L}$ of gallic acid, 1.55 and $1.03 \mathrm{~g} / \mathrm{L}$ of hydroxybenzoic acid were obtained respectively. In most treatments these two polyphenols were found in the largest amounts. In
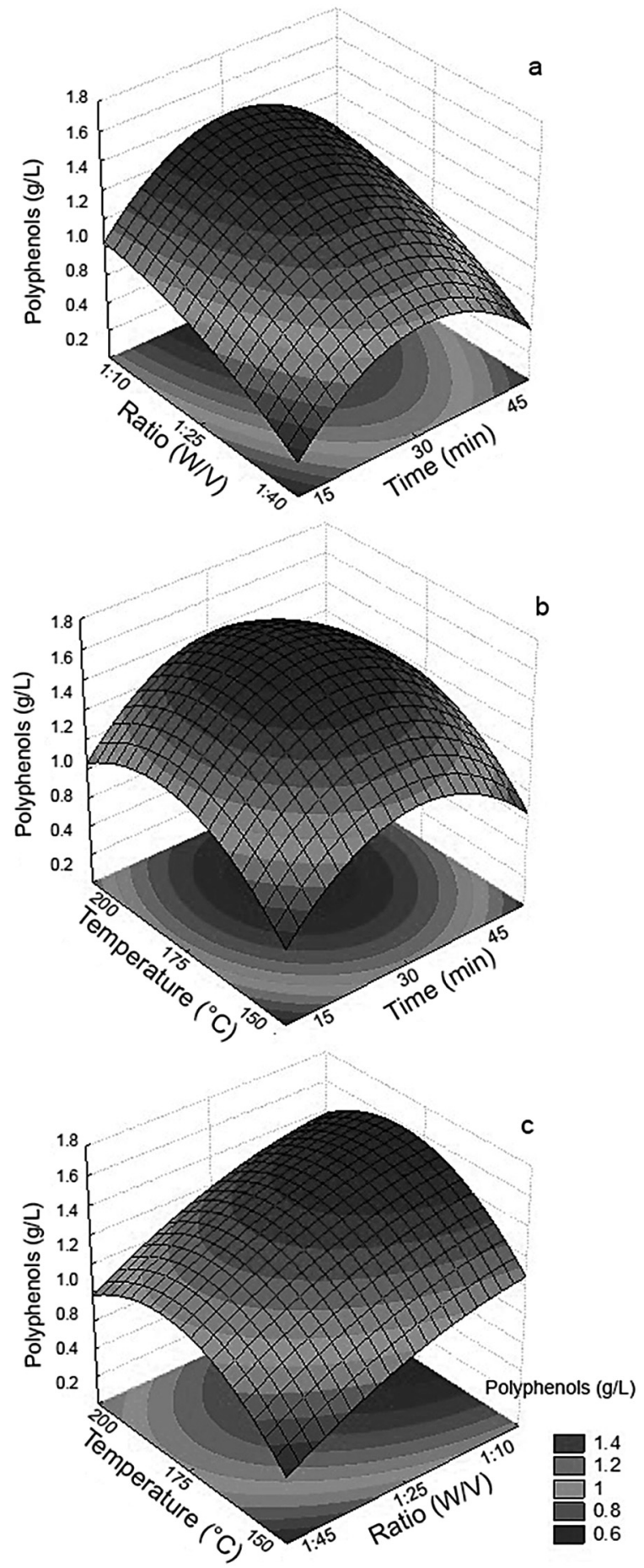

Fig. 4. Response surface plots of the effect of: (a) solid-liquid ratio (w/v) and time (min), (b) temperature $\left({ }^{\circ} \mathrm{C}\right)$ and time $(\mathrm{min})$; and $(\mathrm{c})$ temperature $\left({ }^{\circ} \mathrm{C}\right)$ and solid-liquid ratio $(\mathrm{w} / \mathrm{v})$ on release of polyphenols.

other studies, Rodríguez-Jasso, Mussatto, Pastrana, Aguilar, \& Teixeira, 2014 used the autohydrolysis process for extracting antioxidant compounds from brown seaweed, obtaining $5 \mathrm{mg}$ of total phenolics per $100 \mathrm{mg}$ of sulphated fucan values, these results explained by its chemical nature and low water-solubility. There are few studies on the implementation of autohydrolysis process for polyphenols compounds release from agricultural wastes although different technologies involving high temperatures and pressures and short exposure time have been evaluated. Jun et al., 2009 evaluated extraction with hydrostatic high pressure to obtain polyphenols from green tea leaves, this 


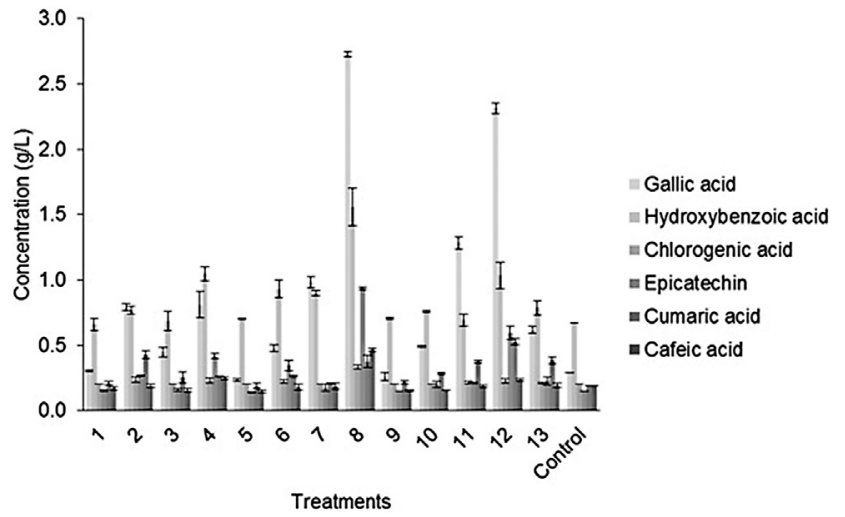

Fig. 5. Concentration of polyphenols in the extracts after the autohydrolysis process. All the concentration values are given in $\mathrm{g} / \mathrm{L}$.

Table 3

Antioxidant activity of the treatments from BBD, a control without autohydrolysis process and gallic acid (GA) at $25 \mathrm{ppm}$ as commercial antioxidant expressed in percentage of radical scavenging activity.

\begin{tabular}{lll}
\hline Treatment & DPPH (RSA \%) & ABTS (RSA \%) \\
\hline 1 & $34.3 \pm 7.9 \mathrm{fg}$ & $83.2 \pm 2.5 \mathrm{c}$ \\
2 & $79.3 \pm 0.9 \mathrm{a}$ & $94.8 \pm 0.2 \mathrm{a}$ \\
3 & $40.5 \pm 2.8 \mathrm{ef}$ & $91.1 \pm 0.7 \mathrm{ab}$ \\
4 & $78.7 \pm 1.1 \mathrm{ab}$ & $94.5 \pm 0.1 \mathrm{a}$ \\
5 & $42.0 \pm 3.4 \mathrm{ef}$ & $85.9 \pm 0.8 \mathrm{bc}$ \\
6 & $82.1 \pm 1.4 \mathrm{a}$ & $94.7 \pm 0.1 \mathrm{a}$ \\
7 & $59.4 \pm 3.0 \mathrm{~d}$ & $89.8 \pm 1.2 \mathrm{ab}$ \\
8 & $67.1 \pm 2.7 \mathrm{c}$ & $94.7 \pm 0.2 \mathrm{a}$ \\
9 & $40.6 \pm 0.8 \mathrm{~h}$ & $84.3 \pm 0.6 \mathrm{ab}$ \\
10 & $80.1 \pm 0.8 \mathrm{a}$ & $95.0 \pm 0.1 \mathrm{a}$ \\
11 & $68.8 \pm 1.8 \mathrm{~cd}$ & $83.4 \pm 1.5 \mathrm{ab}$ \\
12 & $70.6 \pm 0.7 \mathrm{bc}$ & $94.5 \pm 0.1 \mathrm{a}$ \\
13 & $80.2 \pm 0.7 \mathrm{a}$ & $94.7 \pm 0.2 \mathrm{a}$ \\
Control & $27.4 \pm 0.1 \mathrm{~g}$ & $57.1 \pm 0.2 \mathrm{c}$ \\
GA $(25 \mathrm{ppm})$ & $47.1 \pm 0.8 \mathrm{e}$ & $78.0 \pm 1.0 \mathrm{abc}$ \\
\hline
\end{tabular}

Values with different letters in the same column $(\mathrm{a}-\mathrm{h})$ are significantly different according to Tukey's test ( $\mathrm{p}<0.05$ ).

emerging technology allowing for until 30\% polyphenols extraction. Pressurized liquid extraction is other technology that was used to obtain antioxidants compounds from mango leaves. In this work, the temperature is the variable that most influenced the release of antioxidants, being obtained until $<400 \mathrm{mg} / \mathrm{g}$ dry material (FernándezPonce, Casas, Mantell, \& Martínez-de la Ossa, 2015).

\subsection{Antioxidant activity of hydrolysates}

To evaluate the antioxidant activity of the hydrolysates, DPPH and ABTS assays expressed in percentage of radical scavenging activity were performed, as shown in Table 3. All treatments had higher values compared to the control treatment in the two assays evaluated. For DPPH, treatments $2(79.3 \%), 6(82.1 \%), 10(80.1 \%)$ and $13(80.2 \%)$ were statistically significant to the others; and 2.9-fold higher antioxidant activity was obtained when compared to the control. The treatment with the lowest activity was $9(40.6 \%)$. On the other hand in ABTS assay, most of the treatments were not statistically significant and 1.6-fold higher antioxidant activity was observed when compared to the control. The treatment with the lowest activity was 1 (83.2\%). Furthermore all hydrolysates displayed a higher antioxidant activity than the control antioxidant at $25 \mathrm{ppm}$. The correlation between the antioxidant activity and the amount of polyphenols in the treatments is not always positive, this may be to compounds present and that interfere with the spectrophotometric techniques altering the results. It is also possible to synergistic and antagonistic interactions among the antioxidants present (Terpinic, Čeh, Poklar-Ulrih, \& Abramovič, 2012)

Some bioactive compounds such as pyroligneous acid extracted were obtained from the stem and leaves of the pineapple plant using a charcoal kiln for $48 \mathrm{~h}$, reaching up to $89 \%$ and $96 \%$ of radical scavenging activity by DPPH and ABTS assay respectively (Mathew, Zakaria, \& Musa, 2015). In another study, the antioxidant capacity of co-products from the processing of some exotic fruits as pineapple was evaluated (Martínez et al., 2012). Extractions at $30^{\circ} \mathrm{C}$ for $2 \mathrm{~h}$ out with ethyl acetate, methanol and water from pineapple fruit were carried. The results showed a correlation between antioxidant activity and amount of bioactive compounds present in the extracts of pineapple fruit (Hossain \& Rahman, 2011). In a similar research, autohydrolysis was used to extract antioxidant phenolic compounds from spent coffee grounds. The best conditions were $200{ }^{\circ} \mathrm{C}$, liquid-solid ratio of $15 \mathrm{~mL} / \mathrm{g}$ and extraction time of $50 \mathrm{~min}$. They concluded that this process is an eco-friendly and efficient technology to extract antioxidant phenolic compounds (Ballesteros, Teixeira, \& Mussatto, 2017).

\section{Conclusions}

Autohydrolysis is shown to be a promising technique for the valorization of pineapple processing wastes, as it allows for an efficient extraction of the main bioactive compounds and glycosides available. The highest extraction of glucose and fructose was obtained at a temperature of $150{ }^{\circ} \mathrm{C}$ (an extraction time of $30 \mathrm{~min}$ and a solids/liquid ratio of $1: 10 \mathrm{w} / \mathrm{v}$ ) while for the release of total polyphenols the best conditions were $200{ }^{\circ} \mathrm{C}, 30 \mathrm{~min}$ and $1: 10 \mathrm{w} / \mathrm{v}$ ratio. The extraction of polyphenolic compounds as potent antioxidants can be used as food additives. All extracts showed a high antioxidant activity when compared to a commercial antioxidant. The obtained results confirm the importance of pineapple processing wastes as a valuable source of compounds for further use in different application sectors and autohydrolysis as an efficient and environmental friendly technique for its extraction.

\section{Acknowledgment}

The authors thank to BiValBi (Biotechnologies to Valorize the regional food Biodiversity in Latin America) project with reference PIRSES-GA-2013-611493 by financial support. J.A. Teixeira and A. Romaní thank financial support obtained by the Portuguese Foundation for Science and Technology (FCT) under the scope of the strategic funding of UID/BIO/04469/2013 unit and COMPETE 2020 (POCI-010145-FEDER-006684) and BioTecNorte operation (NORTE-01-0145FEDER-000004) funded by European Regional Development Fund under the scope of Norte2020 - Programa Operacional Regional do Norte.

\section{References}

Abdullah (2007). Solid and liquid pineapple waste utilization for lactic acid fermentation using Lactobacillus delbrueckii. Reaktor, 11, 50-52.

Amendola, D., De Faveri, D. M., Egües, I., Serrano, L., Labidi, J., \& Spigno, G. (2012). Autohydrolysis and organosolv process for recovery of hemicelluloses, phenolic compounds and lignin from grape stalks. Bioresource Technology, 107, 267-274.

Ballesteros, L., Teixeira, J. A., \& Mussatto, S. I. (2017). Extraction of polysaccharides by autohydrolysis of spent coffee grounds and evaluation of their antioxidant activity. Carbohydrate Polymers, 157, 258-266.

Ballesteros, L. F., Cerqueira, M. A., Teixeira, J. A., \& Mussatto, S. L. (2015). Characterization of polysaccharides extracted from spent coffee grounds by alkali pretreatment. Carbohydrate Polymers, 127, 347-354.

Ballesteros, L. F., Ramirez, M., Orrego, C. E., Teixeira, J. A., \& Mussatto, S. I. (2017). Optimization of autohydrolysis conditions extract antioxidant phenolic compounds from spent coffee grounds. Journal of Food Engineering, 199, 1-8.

Bradford, M. M. (1976). A rapid sensitive method for quantification of microgram quantities of protein utilizing the principle of protein-dye binding. Analytical Biochemistry, 77(1-2), 248-254.

Chakraborty, S., Srinivasa, P., \& Niwas, H. (2015). Effect of combined high pressuretemperature treatments on color and nutritional quality attributes of pineapple (Ananas comosus L.) puree. Innovative Food Science \& Emerging Technologies, 28, 10-21. 
Conde, E., Moure, A., Domínguez, H., \& Parajó, J. C. (2011). Production of antioxidants by non-isothermal autohydrolysis of lignocellulosic wastes. LWT-Food Science and Technology, 44, 436-442.

Conesa, C., García-Breijo, E., Loeff, E., Seguí, L., Fito, P., \& Laguarda-Miró, N. (2015). An electrochemical impedance spectroscopy-based technique to identify and quantify fermentable sugars in pineapple waste valorization for bioethanol production. Sensors, 15(9), 22941-22955.

Cuevas, M., García, J. F., Hodaifa, G., \& Sánchez, S. (2015). Oligosaccharides and sugars production from olive stones by autohydrolysis and enzymatic hydrolysis. Industrial Crops and Products, 70, 100-106.

Díaz-Vela, J., Totosaus, A., Cruz-Guerrero, A., \& Pérez-Chabela, M. L. (2013). In vitro evaluation of the fermentation of added-value agroindustrial by-products: Cactus pear (Opuntia ficus-indica L.) peel and pineapple (Ananas comosus) peel as functional ingredients. International Journal of Food Science and Technology, 48(7), 1460-1467.

Dreywood, R. (1946). Qualitative test for carbohydrate material. Analytical Chemistry, 18(8), 499.

Dubois, M., Gilles, K. A., Hamilton, J. K., Rebers, P. A., \& Smith, F. (1956). Colorimetric method for determination of sugars related substances. Analytical Chemistry, 28(3), $350-356$.

FAO (2016). Food and agriculture organization of the United Nations. USA: Statistical Division. Retrieved from http://faostat3.fao.org/home/E (accessed july-2016)

Fernández-Ponce, M. T., Casas, L., Mantell, C., \& Martínez-de la Ossa, E. (2015). Use of high pressure techniques to produce Mangifera indica L. leaf extracts enriched in potent antioxidant phenolic compounds. Innovative Food Science \& Emerging Technologies, 29, 94-106.

Gómez, B., Gullón, B., Yáñez, R., Parajó, J. C., \& Alonso, J. L. (2013). Pectic oligosaccharides from lemon peel wastes: Production, purification, and chemical characterization. Journal of Agricultural and Food Chemistry, 61(42), 10043-10053.

Hemalatha, R., \& Anbuselvi, S. (2013). Physicochemical constituents of pineapple pulp and waste. Journal of Chemical and Pharmaceutical Research, 5(2), 240-242.

Hossain, M., \& Rahman, S. M. (2011). Total phenolics, flavonoids and antioxidant activity of tropical fruit pineapple. Food Research International, 44, 672-676.

Jun, X., Deji, S., Shou, Z., Bingbing, L., Ye, L., \& Rui, Z. (2009). Characterization of polyphenols from green tea leaves using a high hydrostatic pressure extraction. International Journal of Pharmaceutics, 382(1-2), 139-143.

Jusoh, N., Othman, N., Idris, A., \& Nasruddin, A. (2014). Characterization of liquid pineapple waste as carbon source for production of succinic acid. Jurnal Teknologi (Sciences \& Engineering), 69(4), 11-13.

Lachos-Pérez, D., Martinez-Jimenes, F., Rezende, C. A., Tompsett, G., Timko, M., \& Forster-Carneiro, T. (2016). Subcritical water hydrolysis of sugarcane bagasse: An approach on solid residues characterization. The Journal of Supercritical Fluids, 108, 69-78.

Larrauri, J. A., Rupérez, P., \& Saura-Calixto, F. (1997). Pineapple shell as a source of dietary fiber with associated polyphenols. Journal of Agricultural and Food Chemistry, 45(10), 4028-4031.

Li, T., Shen, P., Liu, W., Liu, C., Liang, R., Yan, N., \& Chen, J. (2014). Major polyphenolics in pineapple peels and their antioxidant interactions. International Journal of Food Properties, 17(8), 1805-1817.

Lin, C., Koutinas, A., Stamatelatou, K., Mubofu, E., Matharu, A., Kopsahelis, N., ... Luque, R. (2014). Current and future trends in food waste valorization for the production of chemicals, materials and fuels: A global perspective. Biofuels Bioproducts \& Biorefinering, 8(5), 686-715.
Makkar, H. P. S., Blümmel, M., Borowy, N. K., \& Becker, K. (1993). Gravimetric determination of tannins and their correlations with chemical and protein precipitation methods. Journal of the Science of Food and Agriculture, 61(2), 161-165.

Martínez, R., Torres, P., Meneses, M., Figueroa, J., Pérez-Álvarez, J., \& Viuda-Martos, M. (2012). Chemical, technological and in vitro antioxidant properties of mango, guava, pineapple and passion fruit dietary fiber concentrate. Food Chemistry, 135, 1520-1526.

Mathew, S., Zakaria, Z., \& Musa, N. (2015). Antioxidant property and chemical profile of pyroligneous acid from pineapple plant waste biomass. Process Biochemistry, 50, 1985-1992.

Mouré, A., Conde, E., Falqué, E., Domínguez, H., \& Parajó, J. C. (2014). Production of nutraceutics from chestnut burs by hydrolytic treatment. Food Research International $65,359-366$.

Mrabet, A., Rodríguez-Gutiérrez, G., Guillén-Bejarano, R., Rodríguez-Arcos, R., Ferchichi, A., Sindic, M., \& Jiménez-Araujo, A. (2014). Valorization of Tunisian secondary date varieties (Phoenix dactylifera L.) by hydrothermal treatments: New fiber concentrates with antioxidant activity. LWT-Food Science and Technology, 60(1), 518-524.

Parajó, J. C., Domínguez, H., Moure, A., Díaz-Reinoso, B., Conde, E., Soto, M. L., Conde, J., \& González-López, N. (2008). Recovery of phenolic antioxidants released during hydrolytic treatments of agricultural and forest residues. Electronic Journal of Environmental, Agricultural and Food Chemistry, 7(8), 3243-3249.

Rodríguez-Jasso, R. M., Mussatto, S. I., Pastrana, L., Aguilar, C. N., \& Teixeira, J. (2013). Extraction of sulfated polysaccharides by autohydrolysis of brown seaweed Fucus vesiculosus. Journal of Applied Phycology, 25(1), 31-39.

Rodríguez-Jasso, R. M., Mussatto, S. I., Pastrana, L., Aguilar, C. N., \& Teixeira, J. (2014). Chemical composition and antioxidant activity of sulphated polysaccharides extracted from Fucus vesiculosus using different hydrothermal processes. Chemical Papers, 68(2), 203-209.

Ruiz, H. A., Rodríguez-Jasso, R. M., Fernandes, B. D., Vicente, A. A., \& Teixeira, J. A. (2013). Hydrothermal processing, as an alternative for upgrading agriculture residues and marine biomass according to the biorefinery concept: A review. Renewable and Sustainable Energy Reviews, 21, 35-51.

Ruiz, H. A., Vicente, A. A., \& Teixeira, J. A. (2012). Kinetic modeling of enzymatic saccharification using wheat straw pretreated under autohydrolysis and organosolv process. Industrial Crops and Products, 36(1), 100-107.

Sabio, E., Álvarez-Murillo, A., Román, S., \& Ledesma, B. (2015). Conversion of tomatopeel waste into solid fuel by hydrothermal carbonization: Influence of the processing variables. Waste Management, 47, 122-132.

Santana-Méridas, O., González-Coloma, A., \& Sánchez-Vioque, R. (2012). Agricultural residues as a source of bioactive natural products. Phytochemistry Reviews, 11, 447-466.

Seleni, M. M., Canniatti, S. G., dos Santos, C. T., Ratnayake, W. S., Flores, R. A., \& Bianchini, A. (2014). Characterisation and potential application of pineapple pomace in an extruded product for fiber enhancement. Food Chemistry, 163, 23-30.

Silvestre, M., Carreira, R., Silva, M., Corgosinho, F., Monteiro, M., \& Morais, H. (2012) Effect of $\mathrm{pH}$ and temperature on the activity of enzymatic extracts from pineapple peel. Food and Bioprocess Technology, 5(5), 1824-1831.

Terpinic, P., Čeh, B., Poklar-Ulrih, N., \& Abramovič, H. (2012). Studies of correlation between antioxidant properties and total phenolic content of different oil cake extracts. Industrial Crops and Products, 39, 210-217.

Upadhyay, A., Prava-Lama, J., \& Tawata, S. (2010). Utilization of pineapple waste: A review. Journal of Food Science and Technology Nepal, 6, 10-18. 